In classical pernicious anaemia the histological appearances are characteristic and the gastric antrum is not involved (Magnus and Ungley, 1938). The fasting plasma gastrin is invariably elevated (Ganguli, Cullen and Irvine, 1971). Antral gastritis, however, may lead to impaired gastrin release (Strickland et al., 1971) and involvement of the gastric antrum in our patient presumably accounts for the absence of an increased plasma gastrin level. Another unusual feature was the association of iron deficiency with achlorhydria and vitamin $B_{12}$ malabsorption in the absence of detectable parietal cell antibodies (Dagg et al., 1966).

Patients with primary acquired immunoglobulin deficiency may exhibit achlorhydria and malabsorption of vitamin $B_{12}$ (Twomey et al., 1970). These patients, too, differ from those with classical pernicious anaemia, presenting at an earlier age and without detectable humoral antibodies against gastric parietal cells. They do not, however, display granulomata on gastric biopsy.

It is widely accepted that parietal cell antibodies may be involved in the initiation of the process of gastric atrophy in pernicious anaemia (Taylor et al., 1962; Tanaka and Glass, 1970). However, the importance of cell mediated immunity to intrinsic factor is now becoming recognized (Chanarin and James, 1974). The immunoglobulin deficiency, the lack of parietal cell antibodies and the presence of gastric granulomata in our patient, all suggest that cell mediated mechanisms might have been playing a maior role in the pathogenesis of the vitamin $B_{12}$ malabsorption.

\section{Acknowledgments}

We are indebted to Dr D. M. Vickers for the interpretation of the gastric biopsies and to Professor J. M. Evanson for his encouragement and advice.

\section{References}

Chanarin, I. \& James, D. (1974) Humoral and cell-mediated intrinsic-factor antibody in pernicious anaemia. Lancet, i, 1078.

DAGG, J.H., Goldberg, A., Gibbs, W.N. \& Anderson, J.R. (1966) Detection of latent pernicious anaemia in irondeficiency anaemia. British Medical Journal, 2, 619.

Fahimi, D.H., Deren, J.J., Gotrlieb, L.S. \& Zamcheck, N. (1963) Isolated granulomatous gastritis: its relationship to disseminated sarcoidosis and regional enteritis. Gastroenterology, 45, 161.

Ganguli, P.C., Cullen, D.R. \& IRvine, W.J. (1971) Radioimmunoassay of plasma-gastrin in pernicious anaemia, achlorhydria without pernicious anaemia, hypochlorhydria, and in controls. Lancet, i, 155.

MaGNus, H.A. \& UNGley, C.C. (1938) Gastric lesion in pernicious anaemia. Lancet, i, 420.

Strickland, R.G., Bhatual, P.S., Korman, M.G. \& HANSKY, J. (1971) Serum gastrin and the antral mucosa in atrophic gastritis. British Medical Journal, 4, 451.

TANAKA, N. \& Glass, J.G.B. (1970) Effect of prolonged administration of parietal cell antibodies from patients with atrophic gastritis and pernicious anaemia on the parietal cell mass and $\mathrm{HCl}$ output in rats. Gastroenterology, $58,482$.

TAYlor, K.B., RoITt, I.M., Doniach, D., Couchman, K.G. \& Shapland, C. (1962) Autoimmune phenomena in pernicious anaemia: gastric antibodies. British Medical Journal, 2, 1347.

Twomey, J.J., Jordan, P.H., Laughter, A.H., Meuwissen, J.H. \& GooD, R.A. (1970) The gastric disorder in immunoglobulin deficient patients. Annals of Internal Medicine, 72, 499.

\title{
Combination antifungal therapy for cryptococcal meningitis
}

\author{
J. S. Tobias* \\ M.R.C.P. \\ P. F. M. WRIGLEY* \\ Ph.D., M.R.C.P.

\begin{abstract}
Departments of Bacteriology and* Medical Oncology, St Bartholomew's Hospital, London ECI
\end{abstract}

\begin{abstract}
Summary
Two patients with Hodgkin's disease and cryptococcal meningitis are described. Both patients were treated with a combination of the two antifungal agents, amphotericin B and flucytosine. Nephrotoxicity was

* Present address: ICRF Department of Medical Oncology, St Bartholomew's Hospital, London EC1.
\end{abstract}

easily reversible in both patients and clinical improvement was seen with this combination therapy. Intrathecal therapy with amphotericin B was used in both patients. The optimal treatment of this disease may prove to be a combination of oral flucytosine, with amphotericin $B$ given by intrathecal injection as well as rapid low dose intravenous injection. 


\section{Introduction}

Cryptococcal meningitis is a rare disease in Great Britain, and less than a dozen cases are reported to the Mycology Reference Laboratory each year. It is more common in the United States (Diamond and Bennett, 1974) and in Australia (Edwards, Sutherland and Tyrer, 1970) reaching a peak incidence of 4.7 per 100,000 in the tropical north of Queensland. In a recent large series of 111 cases (Diamond and Bennett, 1974), thirty-nine $(35.1 \%)$ patients were receiving steroid therapy or had Hodgkin's disease or other lymphoreticular malignancies.

Untreated, it is rapidly fatal (Geaney, Horsfall and Neilson, 1956), but since the advent of amphotericin $B$ in the late 1950's the infection can be eradicated in at least $75 \%$ of all patients (Spickard et al., 1963; Edwards et al., 1970). However, the value of this agent has always been lessened because of its severe nephrotoxicity; and this has led many clinicians to withhold it even from patients with lethal fungal disease (Symmers, 1970).

The intensive search for a less dangerous antifungal agent led to the development of flucytosine in the early 1960's, and clinical reports of its value in the treatment of cryptococcal infections rapidly appeared (Tassel and Madoff, 1968; McGill et al., 1969; Fass and Perkins, 1971). There have been reports of in vitro synergy with amphotericin B (Medoff, Comfort and Kobayashi, 1971; Medoff et al., 1972), and in the present patients this theoretical background was exploited, both antifungal agents being used concurrently.

\section{Case reports}

(1) A 66-year-old Australian seaman developed stage IIIB Hodgkin's Disease. Combination chemotherapy was given according to the regime of DeVita, Serpick and Carbone (1970) and his lymphadenopathy improved. Fifteen months later he was admitted to hospital with sweating, rigors and pruritus. He had noticed several scabbed lesions on his back and head, and a skin biopsy demonstrated the presence of cryptococci. The lesions progressed rapidly and he developed a low-grade fever. In view of the nature of cryptococcosis in association with Hodgkin's disease a lumbar puncture was considered mandatory and the c.s.f. showed 2 lymphocytes $/ \mathrm{mm}^{3}$, protein $65 \mathrm{mg} \%$ and glucose $85 \mathrm{mg} \%$. The Nigrosin stain revealed yeasts and c.s.f. culture yielded Cryptococcus neoformans in scanty colonies. Cryptococcal antigen was present in the c.s.f. at a titre of $1: 25$ and the blood at a titre of $1: 5$. Tests for cryptococcal antibody in the c.s.f. and blood were negative. The minimal inhibitory concentration (MIC) for both amphotericin B and flucytosine was determined, and found to be $0.6 \mu \mathrm{g} /$ $\mathrm{ml}$ and $1.0 \mu \mathrm{g} / \mathrm{ml}$ respectively. He was initially treated with daily intravenous infusions of amphotericin $\mathrm{B}$, commencing with $20 \mathrm{mg}$ daily and increasing by $20 \mathrm{mg}$ daily to a maximum of $80 \mathrm{mg}$ daily. Within a week his blood urea (previously $32 \mathrm{mg} \%$ ) had risen to $102 \mathrm{mg} \%$ and his creatinine clearance (initially $110 \mathrm{ml} / \mathrm{min}$ ) fell to $28 \mathrm{ml} / \mathrm{min}$. Amphotericin B therapy was discontinued, and he then commenced treatment with flucytosine $1.5 \mathrm{~g}$ /day and intrathecal amphotericin B $(0.5 \mathrm{mg}$ by lumbar puncture at weekly intervals). The levels of both drugs were measured at weekly intervals and were always found to be in excess of the MIC.

After 3 weeks without amphotericin B therapy, during which time his renal function had remained normal, the drug was cautiously reintroduced. It was found that a dosage of $10 \mathrm{mg}$ daily given over $10 \mathrm{~min}$ was sufficient to maintain normal renal function. The flucytosine was continued as before, and from this time onwards his clinical improvement was rapid and he was discharged from hospital 1 month later. The skin lesions resolved completely, and skin scrapings taken before discharge were sterile, as was the c.s.f. Treatment was discontinued. Two months later, having returned to Australia, he became drowsy and developed focal neurological signs suggesting bulbar damage. He was again treated with flucytosine but shortly afterwards died from pneumococcal septicaemia. A post-mortem examination confirmed a region of lytic necrosis in the mid-brain in the middle of which was an actively budding colony of $C$. neoformans.

(2) A 33-year-old man developed Stage 1A nodular sclerosing Hodgkin's disease in 1961. He was treated with mantle radiotherapy, but relapsed in the abdomen in 1968. Treatment with combination chemotherapy was commenced, using the regime of Nicholson et al. (1970). He achieved a complete remission but relapsed again in 1971 with signs suggestive of a space-occupying intracranial lesion. Abnormal brain scan and carotid angiogram supported this diagnosis, and whole brain irradiation was given to a dose of $3000 \mathrm{rad}$ on the assumption that this represented intracerebral Hodgkin's disease. This again resulted in a complete remission, but he was readmitted in January 1974 with headache and dementia. He was semi-conscious, disorientated and dysphasic, with meningism and nystagmus. The c.s.f. was abnormal: cell count showed 9 cells $/ \mathrm{mm}^{3}$ (all lymphocytes); protein was $1.5 \mathrm{~g} \%$ and the glucose was $5 \mathrm{mg} \%$. C. neoformans was not seen in the Nigrosin stain but was cultured from the deposit. The MIC of amphotericin B for the organism was determined to be $0.04 \mu \mathrm{g} / \mathrm{ml}$ and the MIC of flucytosine was found to be $8 \mu \mathrm{g} / \mathrm{ml}$. He was immediately commenced on amphotericin B by fast intravenous injection over $10 \mathrm{~min}$, at a starting dose of $10 \mathrm{mg}$ daily. This was increased over 10 days to a maximum 


\begin{tabular}{|c|c|c|c|c|c|}
\hline & Feb. & Mar. & Apr. & May & Jun. \\
\hline Creatinine clearance $(\mathrm{ml} / \mathrm{min})$ & 72 & 34 & 66 & 47 & 43 \\
\hline Blood urea $(\mathrm{mg} \%)$ & 52 & 90 & 22 & 38 & 36 \\
\hline $\begin{array}{l}\text { Blood } \\
\text { levels }\end{array} \quad\left\{\begin{array}{l}\text { Amph. B }(\mu \mathrm{g} / \mathrm{ml}) \\
\text { FC. }(\mu \mathrm{g} / \mathrm{ml})\end{array}\right.$ & $\begin{array}{l}0 \cdot 2 \\
34\end{array}$ & $\begin{array}{l}0 \cdot 4 \\
80\end{array}$ & $\begin{array}{l}0 \cdot 2 \\
58\end{array}$ & $\begin{array}{l}0.05 \\
42\end{array}$ & $\begin{array}{l}0 \cdot 2 \\
60\end{array}$ \\
\hline $\begin{array}{l}\text { c.s.f. } \\
\text { levels }\end{array} \quad\left\{\begin{array}{l}\text { Amph. B }(\mu \mathrm{g} / \mathrm{ml}) \\
\text { FC. }(\mu \mathrm{g} / \mathrm{ml})\end{array}\right.$ & $34 \cdot 2$ & 30 & & & \\
\hline $\begin{array}{l}\text { c.s.f. antigen titre } \\
\text { Plasma antibody titre }\end{array}$ & $1: 80$ & $1: 40$ & $1: 20$ & 一 & \\
\hline
\end{tabular}

Treatment Systemic FC.

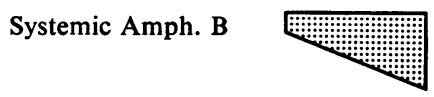

Intrathecal Amph. B filf ศif

FIG. 1. Treatment, drug levels and toxicity in patient 2.

$\mathrm{FC}=$ flucytosine, Amph. B = amphotericin B.

dosage of $50 \mathrm{mg} /$ day. He was also treated with intrathecal amphotericin B via a subcutaneous reservoir (Diamond and Bennett, 1973) as there was some evidence of spinal block which would have led to doubts about the effectiveness of intrathecal treatment by the lumbar route. A dose of $0.5 \mathrm{mg}$ amphotericin B was instilled twice weekly to a total of eight intrathecal injections, at which stage the reservoir developed a block. By this time his improvement was such that intrathecal therapy was discontinued.

In addition, he received large doses ( $6 \mathrm{~g}$ daily) of flucytosine by mouth from the beginning of the illness. Levels of both drugs were measured frequently in the blood and c.s.f. and were always found to exceed the MIC (Fig. 1). Treatment with amphotericin B was discontinued after 6 weeks because of nephrotoxicity, but the renal function rapidly returned to normal after the drug was stopped. The total dose administered was $1.8 \mathrm{~g}$. Progress was monitored by the measurement of antigen and antibody levels (Fig. 1) and from an initial antigen titre of $1: 50$, the level fell to zero after 4 months. There was a concomitant clinical improvement, and by this time the patient was alert, well orientated, and able to read the newspaper with interest.

\section{Discussion}

The advent of powerful antifungal agents over the last 20 years has ensured the survival of large numbers of patients with deep-seated mycotic infections. However cryptococcosis (and in particular cryptococcal meningitis) has remained difficult to treat, partly because of the frequent delay in diagnosis, but also because of the serious side effects of the best known agent, amphotericin B. The demonstration by
Medoff and his colleagues (1972) that there may be a genuine synergy between amphotericin $\mathbf{B}$ and flucytosine led to the use of both these agents concurrently in an attempt to eradicate a serious illness in patients already compromised by widespread Hodgkin's disease. Such patients are more likely to develop cryptococcal meningitis, and their prognosis is especially poor (Diamond and Bennett, 1974). Until very recently, the only patients treated with both agents were those in whom amphotericin B therapy had failed-the flucytosine being used as a second-line drug (Vandevelde, Mauceri and Johnson, 1972). Although combination antifungal therapy has been successfully employed in an animal model (Block and Bennett, 1973) it is not yet clear whether the prognosis of patients treated with both drugs is significantly improved. As flucytosine has been shown to be a relatively non-toxic drug (Utz, 1972), its chief value may well prove to be in the reduction in the amount of amphotericin B required to achieve a cure. It is not wise to use it alone as resistance of the organism so frequently emerges during treatment (Holt and Newman, 1973).

In addition, the use of intrathecal amphotericin B remains controversial. Butler et al. (1964) state that their patients treated in this way had fewer relapses, and Witorsch et al. (1965) recommended the use of the subcutaneous reservoir developed by Ommaya (1963) to instil the antibiotic. More recently, Diamond and Bennett (1973) drew attention to the problems of reservoir insertion, and it may be wise to reserve the use of these reservoirs for patients who fail with more conventional therapy. Although the use of the reservoir is certainly more comfortable for the patient undergoing many intrathecal injections, serious neurological and other 
consequences such as paraplegia, clogging, misplacement, leakage, and wound or c.s.f. infection are unfortunately not uncommon. About $50 \%$ of these patients can be expected to develop complications from insertion or usage. Successful therapy may depend on intraventricular therapy, and this presumably contributed to the very high c.s.f. amphotericin B levels seen in patient 2 (Fig. 1).

Fields, Bates and Abernathy (1970) showed that rapid infusion ( $45 \mathrm{~min}$ ) of amphotericin $B$ led to higher serum levels than treatment with the more usual prolonged infusion (4-6 hr). In the cases discussed here it has been confirmed that this rapid infusion method is safe and effective. When combined with oral flucytosine it provides an effective regime for treatment of fungal infections. It has been suggested (Wees and Schope, 1972) that the combination of flucytosine and low dose amphotericin B might overcome problems of drug resistance without causing nephrotoxicity, and this may in future prove to be the ideal therapy for cryptococcal meningitis.

\section{Acknowledgment}

We are most grateful to Dr D. W. R. Mackenzie and his staff at the Mycological Reference Laboratory of the Public Health Laboratory Service for identifying and sensitivitytesting of the strain of Cryptococcus neoformans and for regularly assaying serum and c.s.f. for flucytosine, amphotericin B, crytococcal antigen and antibody.

\section{References}

BLoCK, E.R. \& BENNETT, J.E. (1973) The combined effect of 5-fluorocytosine and amphotericin-B on the therapy of murine cryptococcosis. Proceedings of the Society for Experimental Biology and Medicine, 142, 476.

Butler, W.T., Alling, D.W., Spickard, A. \& Utz, J.P. (1964) Diagnostic and prognostic value of clinical and laboratory findings in cryptococcal meningitis. New England Journal of Medicine, 270, 59.

DeVita, V.T., Serpick, A.A. \& Carbone, P.P. (1970) Combination chemotherapy in the treatment of advanced Hodgkin's disease. Annals of Internal Medicine, 73, 881.

DiAmond, R.D. \& BENNETT, J.E. (1973) A subcutaneous reservoir for intrathecal therapy of fungal meningitis. New England Journal of Medicine, 288, 186.

Diamond, R.D. \& BennetT, J.E. (1974) Prognostic factors in cryptococcal meningitis: a study in 111 cases. Annals of Internal Medicine, 80, 176.
Edwards, V.E., Sutherland, J.M. \& TYRer, J.H. (1970) Cryptococcosis of the central nervous system: epidemiological, clinical and therapeutic features. Journal of Neurology, Neurosurgery and Psychiatry, 33, 415.

FASS, R.J. \& Perkins, R.L. (1971) 5-Fluorocytosine in the treatment of cryptococcal and Candida mycoses. Annals of Internal Medicine, 74, 535.

Fields, B.T., Bates, J.H. \& Abernathy, R.S. (1970) Amphotericin-B serum concentrations during therapy. Applied Microbiology, 19, 955.

Geaney, B., Horsfall, W.R. \& Neilson, G. (1956) Torulosis in Queensland: report of fourteen cases. Medical Journal of Australia, 2, 378.

Holt, R.J. \& Newman, R.L. (1973) The antimycotic activity of 5-fluorocytosine. Journal of Clinical Pathology, 26, 167.

McGill, P.E., Sequeira, R., Jindani, A., Nguli, E.T., Forrester, A.T.T. \& Fulton, W.F.M. (1969) 5-Fluorocytosine in the treatment of cryptococcal meningitis. East African Medical Journal, 46, 663.

Medoff, G., Comfort, M. \& Kobayashi, G.S. (1971) Synergistic action of amphotericin-B and 5-fluorocytosine against yeast-like organisms. Proceedings of the Society for Experimental Biology and Medicine, 138, 571.

Medoff, G., Kobayashi, G.S., Kwan, C.N., Schlessinger, D. \& Venkov, P. (1972) Potentiation of rifampicin and 5fluorocytosine as antifungal antibiotics by amphotericinB. Proceedings of the National Academy of Sciences of the United States of America, 68, 196.

Nicholson, W.M., Beard, M.E.J., Crowther, D., StansFeld, A.G., Vartan, C.T., MalPas, J.S., Hamilton Fairley, G. \& Bodley Scott, R. (1970) Combination chemotherapy in generalized Hodgkin's Disease. British Medical Journal, 3, 7.

OmmayA, A.K. (1963) Subcutaneous reservoir and pump fo sterile access to ventricular cerebrospinal fluid. Lancet, i 983.

Spickard, A., Butler, W.T., Andriole, V. \& Utz, J.P? (1963) The improved prognosis of cryptococcal meningitis with amphotericin-B therapy. Annals of Internal Medicine, 58, 66.

Symmers, W. ST. C. (1973) Amphotericin pharmacophobia. British Medical Journal, 4, 460.

TAssel, D. \& Madoff, M.A. (1968) Treatment of Candida sepsis and Cryptococcus meningitis with 5-fluorocytosine: a new antifungal agent. Journal of the American Medical Association, 206, 830.

Vandevelde, A.G., Mauceri, A.A. \& Johnson, J.E. (1972) 5 -Fluorocytosine in the treatment of mycotic infections. Annals of Internal Medicine, 77, 43.

WeEs, W.C. \& SCHOPE, R.W. (1972) 5-Fluorocytosine therapy (correspondence). Annals of Internal Medicine, 77, 1003.

Witorsch, P., Williams, T., Ommaya, A.K. \& Utz, J.P. (1965) Intraventricular administration of amphotericin-B. Journal of the American Medical Association, 194, 699.

UtZ, J.P. (1972) Flucytosine. New England Journal of Medicine, 286, 777. 